\title{
Postoperative complications with neuromuscular blocking drugs and/or reversal agents in obstructive sleep apnea patients: a systematic review
}

Khawaja Rashid Hafeez ${ }^{1}$, Arvind Tuteja', Mandeep Singh ${ }^{1,2,3}$, David T. Wong ${ }^{1}$, Mahesh Nagappa ${ }^{4}$, Frances Chung ${ }^{1}$ and Jean Wong ${ }^{1,2^{*}}$ (D)

\begin{abstract}
Background: Neuromuscular blocking drugs (NMBD) are administered intra-operatively to facilitate intubation and to achieve muscle relaxation for surgical procedures. Incomplete reversal of NMBD can lead to adverse events in the postoperative period. Patients with obstructive sleep apnea (OSA) may be at higher risk of complications related to the use of NMBD. The objectives of this systematic review were to determine whether: 1) OSA patients are at higher risk of postoperative complications from the use of NMBD than non-OSA patients, and 2) the choice of NMBD reversal agent affects the risk of postoperative complications in OSA patients.
\end{abstract}

Methods: A literature search of multiple databases was conducted up to April 2017. The inclusion criteria were: (1) adult surgical patients ( $\geq 18$ years old) with OSA diagnosed by polysomnography, or history, or suspected by screening questionnaire; (2) patients who were given NMBD and/or NMBD reversal agents intraoperatively; (3) reports on postoperative adverse events, particularly respiratory events were available; (4) published studies were in English; and (5) RCTs or observational cohort studies. The quality of evidence was determined by the Oxford Center for Evidence Based Medicine levels of evidence.

Results: Out of 4123 studies, five studies (2 RCTs and 3 observational studies) including 1126 patients were deemed eligible. These studies were heterogeneous precluding a meta-analysis of the results. Two of three studies (1 RCT, 2 observational studies) reported that OSA patients given NMBD may be at higher risk of developing postoperative pulmonary complications (PPCs) like hypoxemia, residual neuromuscular blockade or respiratory failure compared to non-OSA patients. Two studies (1 RCT, 1 observational study) reported that OSA patients who were reversed with sugammadex vs. neostigmine had less PPCs and chest radiographic changes, but the quality of the included studies was Oxford level of evidence: low to moderate.

Conclusions: OSA patients who receive intraoperative NMBD may be at higher risk for postoperative hypoxemia, respiratory failure and residual neuromuscular blockade compared to non-OSA patients. There is some, albeit very limited evidence that NMBD reversal with sugammadex may be associated with less PPCs than neostigmine in patients with OSA. More high-quality studies are needed.

Keywords: Obstructive sleep apnea, Postoperative pulmonary complications, Residual neuromuscular blockade, Neuromuscular blocking agents, Reversal of neuromuscular blocking agents

\footnotetext{
*Correspondence: jean.wong@uhn.ca

'Department of Anesthesia, Toronto Western Hospital, University Health

Network, University of Toronto, 2-405 McLaughlin Wing, 399 Bathurst Street,

Toronto, ON M5T 2S8, Canada

${ }^{2}$ Department of Anesthesia, Women's College Hospital, Toronto, ON, Canada

Full list of author information is available at the end of the article
}

(c) The Author(s). 2018 Open Access This article is distributed under the terms of the Creative Commons Attribution 4.0 International License (http://creativecommons.org/licenses/by/4.0/), which permits unrestricted use, distribution, and reproduction in any medium, provided you give appropriate credit to the original author(s) and the source, provide a link to the Creative Commons license, and indicate if changes were made. The Creative Commons Public Domain Dedication waiver (http://creativecommons.org/publicdomain/zero/1.0/) applies to the data made available in this article, unless otherwise stated. 


\section{Background}

Obstructive sleep apnea (OSA) is a common form of sleep disordered breathing (SDB). The prevalence has increased over the last two decades in association with the rise of the obesity epidemic [1]. It has been estimated that $13 \%$ of men and $6 \%$ of women between 30 and 70 years of age have moderate to severe SDB [2]. Its prevalence is even higher in surgical patients [3, 4]. The severity of OSA often worsens after surgery [5] and patients with OSA are at increased risk of postoperative complications, including serious respiratory complications [6-10].

Neuromuscular blocking drugs (NMBD) are widely used intraoperatively to facilitate tracheal intubation and surgical relaxation [11]. These agents act on acetylcholine receptors at the neuromuscular junction to block neurotransmission and hence, decrease airway tone and blunt the protective airway reflexes [12, 13]. However, NMBD have been reported to have residual effects in the postoperative period even after the administration of reversal agents, potentially causing adverse respiratory outcomes [14-16] like decreased inspiratory flow [17], upper airway obstruction, oxygen desaturation, impaired airway protective reflexes, pneumonia, muscle weakness and reintubation in the postoperative period $[13,18,19]$. Residual neuromuscular blockade (NMB) is common and even mild degrees of residual paralysis can have serious clinical consequences [20]. Reversal agents to NMBD are used to antagonize their effects [21]. There are two types of agents; the anticholinesterases (such as neostigmine) and cyclodextrins (sugammadex) [22]. Sugammadex is a newer reversal agent for aminosteroidal NMBD that reverses moderate to deep neuromuscular blockade [22].

OSA patients may be more vulnerable than non-OSA patients to postoperative complications due to NMBD and inadequate reversal of NMBD. The effect of reversal agents on the occurrence of postoperative complications in OSA patients is uncertain, however, sugammadex may have advantages over neostigmine in this patient population.

The purpose of this systematic review is to determine whether: 1) OSA patients who received NMBD as part of general anesthesia may be at higher risk for developing postoperative complications than non-OSA patients who received NMBD; and 2) the choice of NMBD reversal agent affects the risk of postoperative complications in patients with OSA. This review was prepared as part of the Society of Anesthesia and Sleep Medicine's committee on a guideline for intraoperative management of adult patients with OSA.

\section{Methods}

\section{Search strategy and study selection}

A literature search was performed according to the Preferred Reporting Items for Systematic Reviews guidelines [23]. The search strategy was carried out with the help of a research librarian familiar with literature searches for systematic reviews. We screened published articles describing postoperative complications in surgical patients with OSA and/or obesity who were given NMBD and/ or reversal agents intraoperatively. We included articles that described residual NMB. The literature databases searched were MEDLINE (1946 to April 4, 2017), ePub ahead of print, MEDLINE in-process, and other non-indexed citations (up to April 4, 2017), Embase (1947 to April 4, 2017), Cochrane Central Register of Controlled Trials (up to February, 2017), Cochrane Database of Systematic Reviews (2005 to April 4, 2017), PubMed (1946 to April 4, 2017), Web of Science (1900 to April 4, 2016), Scopus (1960 to April 4, 2017), ClinicalTrials.Gov (up to April 6, 2017), WHO ICTRP (up to April 6, 2017).

The search terms included the Medical Subject Heading keywords "obstructive sleep apnea," "obesity" and "neuromuscular blockade". The following text keywords were used for the literature search: "obstructive sleep apnea syndrome," "sleep disordered breathing," "obesity hypoventilation syndrome," "apnea or apnoea," "hypopnea or hypoapnea," "muscle relaxant," "rocuronium," "atracurium," "cis-atracurium," "vecuronium," "mivacurium," "suxamethonium or succinylcholine," "rapacuronium," "pancuronium," "skeletal muscle relaxant," "neuromuscular reversal agents," "neostigmine," "edrophonium," "sugammadex," "residual neuromuscular block," "neuromuscular blockade reversal," "postoperative residual neuromuscular blockade," "post-extubation complications", "perioperative complications," and "postoperative complications."

Inclusion criteria were: (1) adult surgical patients ( $\geq 18$ years old) with OSA confirmed by polysomnography (PSG), history, or suspected by screening questionnaire; (2) patients in the study were given NMBD and/ or NMBD reversal agents intraoperatively; (3) reports on postoperative adverse events, particularly respiratory events were available (4) published studies were in English and (5) randomized controlled trials (RCTs) or observational cohort studies. Exclusion criteria were: 1) case reports and review articles; 2) studies with no information on OSA status; and 3) studies with no information on postoperative pulmonary complications (PPCs) and/or residual NMB.

Studies were selected independently by 2 reviewers ( $\mathrm{RH}$ and $\mathrm{AT}$ ) who screened the titles and abstracts to determine whether the studies met the eligibility criteria. Disagreements in screening and data extraction were resolved by consulting another author (MS or JW). A citation search by manual review of references from primary or review articles was also performed.

\section{Data extraction}

The following information was collected from each study: author, year of publication, type of study, sample 
size of OSA and non-OSA group, OSA status (diagnosed or suspected), apnea hypopnea index (AHI), PSG data, and sleep questionnaire data, type of surgery, age, gender, body mass index, NMBD used and dose, NMBD reversal agent used and dose, neuromuscular monitoring, postoperative complications, incidence and type of complication.

PPCs included were airway obstruction, hypoxemia and desaturation, decreased inspiratory capacity, respiratory muscle weakness, residual NMB, increased secretions, bronchospasm, atelectasis, pleural effusion, pulmonary edema, respiratory failure, apnea, respiratory failure, re-intubation, postoperative mechanical ventilation and intensive care unit (ICU) admission. We contacted the authors of the studies for missing data. Only one responded [24].

\section{Study quality assessment}

The risk of bias was evaluated using the Cochrane risk of bias tool [24] for RCTs. For observational cohort studies, the Newcastle-Ottawa tool [25] was used to rate risk of bias and study quality by assessing the selection, comparability and outcome of each study. For evaluation of the quality of evidence, we utilized the Oxford Center for Evidence Based Medicine Levels of Evidence [26].

\section{Results}

\section{Study selection}

Our initial electronic search identified 4123 articles, of which four studies were included in the qualitative synthesis (Fig. 1). Forty-five articles were further obtained through citation search and one was included. Three studies describing PPCs in OSA and non-OSA patients were excluded because the number of OSA patients with PPCs was not clearly shown [27-29]. Finally, five studies with at total of 1126 patients were included in this systematic review [30-34].

\section{Study characteristics}

Among the 5 included studies, 2 were RCTs [32, 33] with 426 patients and 3 were observational studies [30, 31, 34] with 700 patients. These were single-center studies from various countries including the United States, Brazil, Turkey and Spain. The types of surgery included were intra-abdominal, bariatric, musculoskeletal, head and neck and otolaryngology surgeries. Descriptive data of the study population are summarized in Table 1. Altogether, $587 \mathrm{di}-$ agnosed or suspected OSA patients and 539 non-OSA patients were included. Three studies reported postoperative complications in OSA vs. non-OSA patients who received NMBD [30-32] and 2 reported postoperative complications in OSA patients administered sugammadex vs. neostigmine [33, 34]. One study [30] used the Berlin questionnaire along with preoperative polysomnography to diagnose OSA, and in another study [31], the authors used STOP-BANG criteria for OSA risk assessment. In the other three studies, patients were already diagnosed with OSA. All the included studies used the TOF watch for intraoperative $\mathrm{NMB}$ monitoring. In PACU, only Pereira et al. used the TOF Watch for residual NMB monitoring. Unal et al. performed clinical assessment of muscle strength in PACU.

The definitions of postoperative pulmonary complications varied between the different studies (Table 2). Some studies did not define the PPCs or included minor symptoms that are not consistent with previous studies reporting PPCs. Only one study described cardiac complications [33]. The details of postoperative adverse events from each study are shown in Table 3.

\section{Risk of Bias}

The risk of bias in both RCTs was moderate overall (Table 4). The risk of bias was fair in the observational studies by Ahmed et al. [30] and Llaurado et al. [34] and that of Pereira et al. [31] was good (Table 5). The quality of all studies was moderate to low (Table 1).

Are patients with OSA who received NMBD as part of general anesthesia at higher risk for postoperative complications than patients without OSA?

We identified one RCT [32] and 2 observational studies $[30,31]$ with 378 diagnosed or suspected OSA patients and 345 non-OSA patients. Since the studies were heterogeneous and differed in study design, types of surgery, and outcomes reported, a meta-analysis was not performed.

In a RCT of 352 patients, Sudre et al. found that OSA vs. non-OSA patients were at higher risk of developing respiratory failure (OR 6.88, 95\% CI 2.36$20.05, P=0.0004$ ) [32]. In an observational study of 40 patients, Ahmed et al. reported that OSA was not an independent risk for postoperative hypoxemia in the first $24 \mathrm{~h}$ after laparoscopic bariatric surgery $(P=0.97)$ [30]. In another observational study of 340 patients, Pereira et al. [31] showed that patients with high risk of OSA (STOP-Bang score $\geq 3$ ) vs. low risk patients (STOP-Bang 0-2) more frequently experienced residual NMB ( $24 \%$ vs. $17 \%, P=0.035$ ), and mild/moderate hypoxia ( $9 \%$ vs. $3 \%$, $P=0.012$ ). There was no significant difference in other respiratory complications between OSA vs. non-OSA patients who received NMBD [30-32]. Based on the included studies, OSA vs. non-OSA patients who have received NMBD may be at higher risk of hypoxemia, residual $\mathrm{NMB}$ and respiratory failure (Oxford LOE between 2 and 3) (Table 1).

Does the choice of NMBD reversal agent affect the risk of postoperative complications in OSA patients?

We identified one RCT [33] and one observational study [34] with a total of 206 OSA patients that evaluated the impact of reversal agents on postoperative 


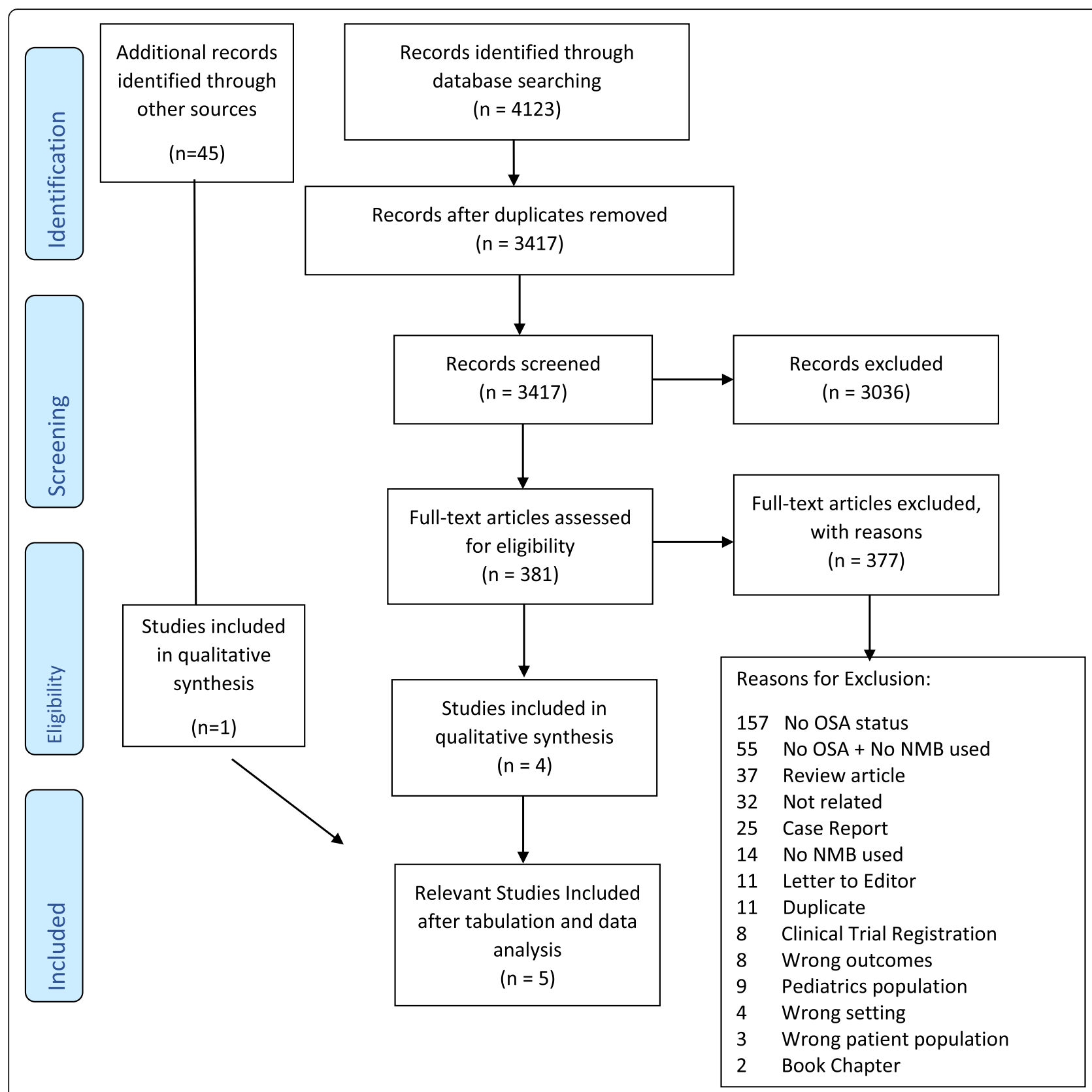

Fig. 1 Flow chart of study selection

complications (Table 2). Two reversal agents, sugammadex and neostigmine, were compared.

In the RCT of 74 OSA patients, Unal et al. found that sugammadex decreases the incidence of PPCs \{desaturation, hypoxemia, apnea, airway manipulation, airway usage, re-intubation, CPAP (continuous positive airway pressure), invasive mechanical ventilation (Table 3)\}. Eight patients $(21.6 \%)$ had significant bradycardia $(P=0.028)$ with six requiring treatment with atropine [33]. In an observational study of 145 OSA patients undergoing laparoscopic bariatric surgeries, sugammadex was found to decrease the incidence of postoperative chest radiograph changes atelectasis, pleural effusions $(P=0.007)$ \} compared with a historical cohort receiving neostigmine. No difference in clinical outcomes including postoperative mechanical ventilation or hospital stay was found [34]. Oxford LOE for both studies was between low to moderate (Table 1).

\section{Discussion}

To date, this systematic review is the first to examine the association of NMBD with PPCs in OSA vs. 


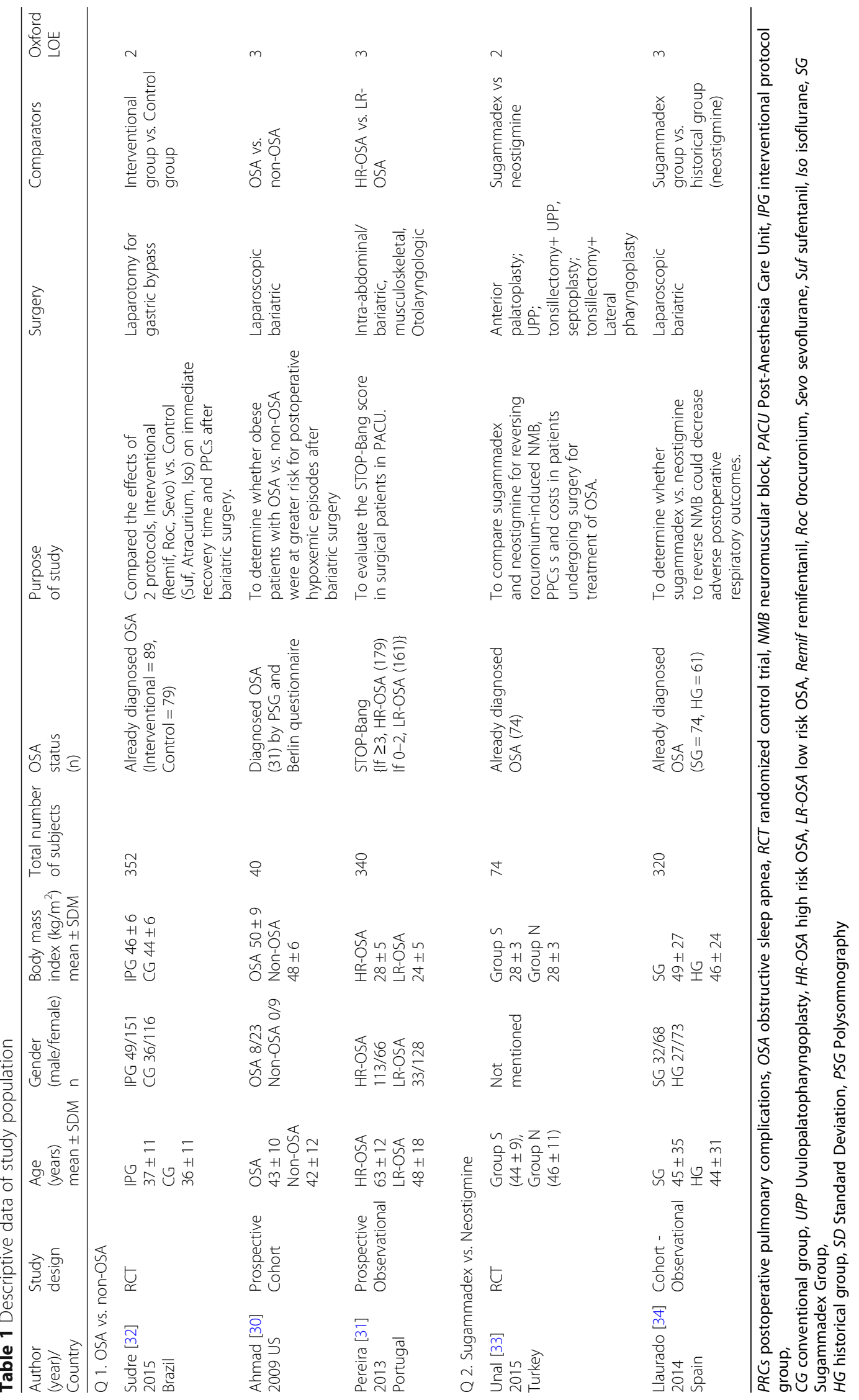


Table 2 Definitions of postoperative pulmonary complications (PPCs)

\begin{tabular}{|c|c|c|}
\hline Studies & PPCs & Definitions \\
\hline \multirow[t]{2}{*}{$\begin{array}{l}\text { Sudre [32] } \\
\text { (2015) }\end{array}$} & $\begin{array}{l}\text { Atelectasis, pleural effusion, } \\
\text { acute pulmonary edema }\end{array}$ & Chest radiograph findings. \\
\hline & Respiratory failure & Not defined \\
\hline $\begin{array}{l}\text { Ahmed [30] } \\
\text { (2009) }\end{array}$ & Hypoxemia & $\begin{array}{l}\mathrm{SpO}_{2}>4 \% \text { below preoperative baseline } \\
\text { values for }>10 \mathrm{~s} \text { in duration. }\end{array}$ \\
\hline \multirow[t]{5}{*}{$\begin{array}{l}\text { Pereira [31] } \\
\text { (2013) }\end{array}$} & Hypoxemia & $\begin{array}{l}\text { Mild-moderate hypoxia }\left(\mathrm{SpO}_{2} \text { of } 93-90 \% \text { ) on } 3 \mathrm{~L} \text { nasal cannula } \mathrm{O}_{2} \text {, }\right. \\
\text { not improved after active interventions (increasing } \mathrm{O}_{2} \text { flows to }>3 \mathrm{~L} / \mathrm{min} \text {, } \\
\text { application of high-flow face mask } \mathrm{O}_{2} \text {, verbal requests to breathe deeply } \\
\text { and tactile stimulation); } \\
\text { Severe hypoxia (SpO2 }<90 \% \text { ) on } 3 \mathrm{~L} \text { nasal cannula } \mathrm{O} 2 \text { not improved after active interventions } \\
\text { (increasing } \mathrm{O}_{2} \text { flows to }>3 \mathrm{~L} / \mathrm{min} \text {, application of high-flow } \\
\text { facemask } \mathrm{O}_{2} \text {, verbal requests to breathe deeply, and tactile stimulation). }\end{array}$ \\
\hline & Respiratory failure & $\begin{array}{l}\text { Signs of respiratory distress or impending ventilatory failure (respiratory rate }>20 \text { breaths per } \\
\text { minute, accessory muscle use, and tracheal tug). }\end{array}$ \\
\hline & Airway obstruction & $\begin{array}{l}\text { Patient complaining of symptoms of respiratory or upper airway muscle weakness } \\
\text { (difficulty breathing, swallowing, or speaking), requiring reintubation in the PACU. }\end{array}$ \\
\hline & Residual NMB & $\begin{array}{l}\text { TOFR }<0.9 \text { and was quantified at PACU admission using acceleromyography of the } \\
\text { adductor pollicis muscle (TOF-Watch }{ }^{\oplus} \text {. }\end{array}$ \\
\hline & $\begin{array}{l}\text { Others } \\
\text { (airway obstruction, muscle weakness, } \\
\text { decreased inspiratory capacity, } \\
\text { bronchospasm) }\end{array}$ & Not defined. \\
\hline \multirow{4}{*}{$\begin{array}{l}\text { Unal [33] } \\
(2015)\end{array}$} & Hypoxemia & $\mathrm{SpO}_{2} \leq 90 \%$ in PACU. \\
\hline & Airway obstruction & Requiring an intervention (jaw thrust, oral or nasal airway, intubation). \\
\hline & Apnea & Not defined. \\
\hline & $\begin{array}{l}\text { Re-intubation \& invasive } \\
\text { postoperative mechanical ventilation. }\end{array}$ & $\begin{array}{l}\text { Patient whose hypoxemia and airway obstruction did not improve despite the application } \\
\text { of oxygen through a mask and airway maneuvers. }\end{array}$ \\
\hline $\begin{array}{l}\text { Llaurado } \\
\text { [34] (2014) }\end{array}$ & Atelectasis, pleural effusion & Chest radiograph finding. \\
\hline
\end{tabular}

PPCs postoperative pulmonary complications, $\mathrm{SPO}_{2}$ Oxygen saturation, $\mathrm{O}_{2}$ Oxygen, $P A C U$ Post anesthesia care unit, NMB neuromuscular blockade, TOFR train of four ratio

non-OSA patients, and the impact of NMBD reversal agents on PPCs in patients with OSA. Though the evidence is limited, our systematic review suggests that OSA patients who are given NMBD may be at a higher risk for hypoxemia, residual NMB and respiratory failure than non-OSA patients. As well, 2 studies reported that OSA patients who received sugammadex have less postoperative complications than those receiving neostigmine, however the studies were of low quality.

\section{OSA vs. non-OSA}

There is growing concern that residual NMB is associated with adverse respiratory outcomes in patients undergoing anesthesia [22, 35-38]. Residual NMB is particularly important to avoid in OSA patients since OSA is associated with an increased risk of postoperative respiratory and cardiac events, ICU transfers, and longer hospital stay $[6-8,39,40]$. Anatomical risk factors increase vulnerability to airway collapse during sedation or sleep in OSA patients. The retropalatal, retroglossal and hypopharyngeal regions of the upper airway in OSA patients are the most common sites of collapse during sleep or sedation, causing obstruction [41]. This collapse can occur because of variations in transmural pressure, such as decreased intraluminal pressure or increased external tissue pressure, or a reduction in the longitudinal tension on the pharynx [42]. Magnetic resonance imaging (MRI) studies show that the airway in OSA patients is different from the normal airway because of thicker lateral pharyngeal walls with an anteroposterior elliptical configuration, unlike the horizontal configuration in the normal airway leading to airway narrowing [42].

Upper airway dilators are more vulnerable to the effects of NMBD compared to the respiratory pump muscles $[6,15]$. Even at levels producing mild blockade, as measured by train of four ratio (TOFR) 0.7-.9, NMBD increased upper airway collapsibility and impaired compensatory genioglossus response to negative pharyngeal pressure challenges [43]. Due to the pathophysiology of the disease, patients with OSA may have increased vulnerability to the effects of NMBD and reversal agents $[42,43]$. In a large retrospective database study of 530,089 patients with 32,789 diagnosed OSA patients, 


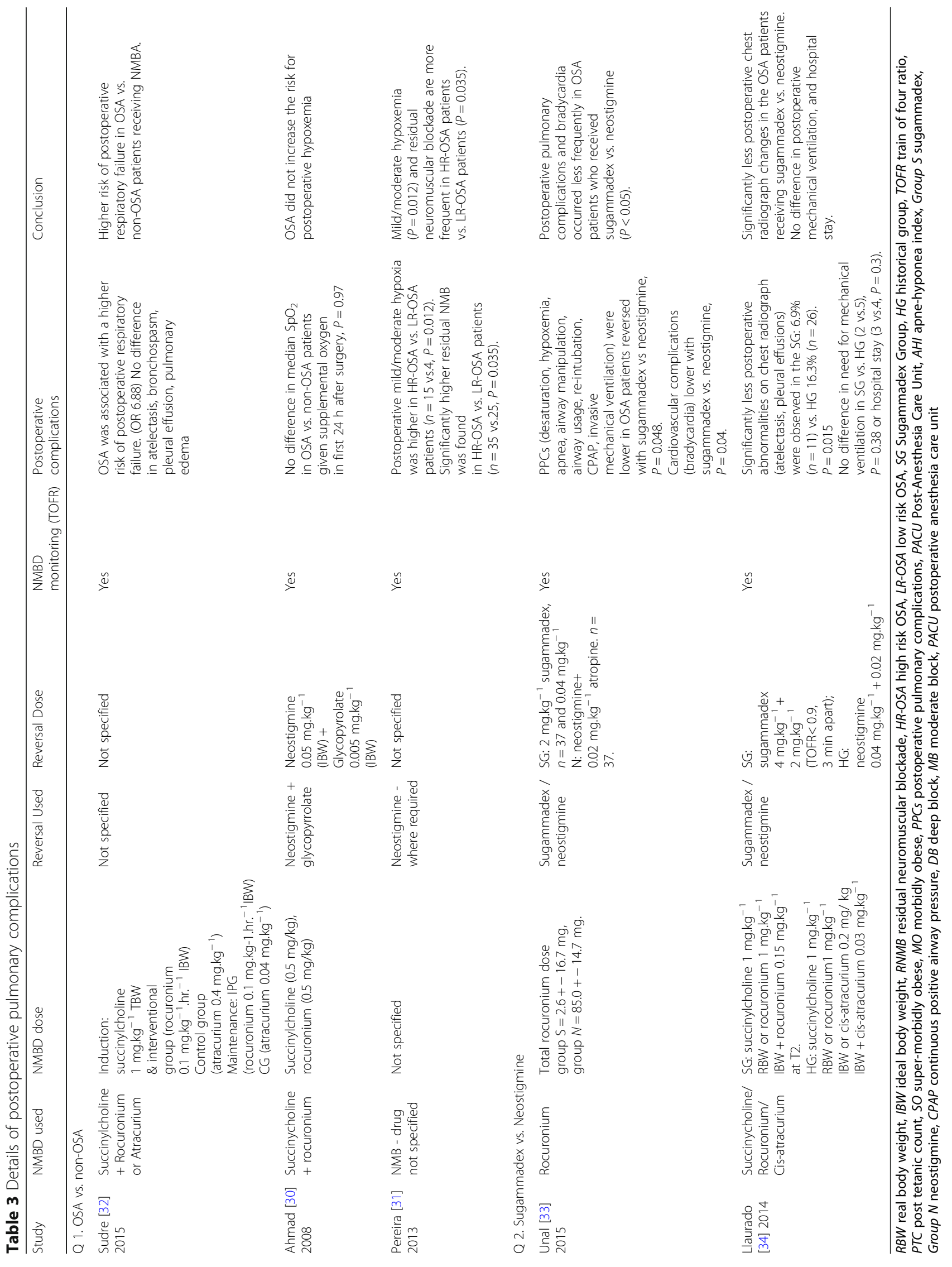


Table 4 Cochrane Risk of Bias in Included Studies

\begin{tabular}{|c|c|c|c|c|c|c|c|}
\hline $\begin{array}{l}\text { First } \\
\text { author (yr) }\end{array}$ & $\begin{array}{l}\text { Adequate sequence } \\
\text { generation }\end{array}$ & $\begin{array}{l}\text { Allocation } \\
\text { concealment }\end{array}$ & Blinding & $\begin{array}{l}\text { Blinding of } \\
\text { outcome } \\
\text { assessment }\end{array}$ & $\begin{array}{l}\text { Incomplete } \\
\text { outcome data } \\
\text { assessed }\end{array}$ & $\begin{array}{l}\text { Free of selective } \\
\text { outcome reporting }\end{array}$ & $\begin{array}{l}\text { Free of } \\
\text { other biases }\end{array}$ \\
\hline Unal (2015) [33] & Unclear & Unclear & Unclear & Unclear & Yes & Yes & Yes \\
\hline Sudre (2015) [32] & Unclear & Unclear & Unclear & Yes & Yes & Yes & Unclear \\
\hline
\end{tabular}

Memtsoudis et al. [8] found a 5-fold increase in intubation and mechanical ventilation in OSA patients after orthopedic surgery and a 2-fold increase after general surgery compared with non-OSA patients. They concluded that OSA is an independent risk factor for developing pulmonary complications [8].

In our review, two observational studies found contrary results for hypoxemia [30,31]. Ahmed et al. found that OSA patients were not at higher risk of developing hypoxemia than non-OSA patients. A significant limitation is the small sample size $(n=41$; OSA $=31$, non-OSA $=9)$.
Also, the use of supplemental oxygen at 31 per min via nasal cannula for $24 \mathrm{~h}$ postoperatively in all patients may have masked the occurrence of desaturation episodes. The incidence of hypoxemia was significantly higher in morbidly obese patients with or without OSA, suggesting the importance of morbid obesity as an independent risk factor for PPCs [30]. Pereira et al. concluded that mild/moderate hypoxia was the only PPC in the immediate postoperative period that occurred more frequently in patients with suspected OSA [31]. Schumann et al. studied the relation between metabolic syndrome and surgical

Table 5 Newcastle-Ottawa Scale

\begin{tabular}{|c|c|c|c|c|c|c|c|c|c|c|c|c|c|c|}
\hline \multicolumn{14}{|c|}{ Quality of Included Studies Assessed by Using the Newcastle-Ottawa Quality Scale for Comparative Studies } & \multirow{4}{*}{ Total } \\
\hline \multirow[t]{3}{*}{ Study } & \multirow{3}{*}{$\begin{array}{l}\text { Study } \\
\text { design }\end{array}$} & \multicolumn{6}{|c|}{ Selection (Max = 4 stars) } & \multirow{2}{*}{\multicolumn{2}{|c|}{$\frac{\text { Comparability }(\text { Max }=2 \text { Stars })}{1}$}} & \multicolumn{4}{|c|}{ Outcome (Max = 3Stars) } & \\
\hline & & \multicolumn{2}{|l|}{1} & 2 & \multicolumn{2}{|l|}{3} & 4 & & & \multicolumn{2}{|l|}{1} & 2 & 3 & \\
\hline & & $A^{*}$ & $B^{*} C D$ & $A^{*} B \quad C$ & $A^{*}$ & $B^{*} C D$ & $A^{*} B$ & $A^{*}$ & $B^{*}$ & $A^{*}$ & $B^{*} C D$ & $A^{*} \quad B$ & $A^{*} B^{*} \quad C \quad D$ & \\
\hline $\begin{array}{l}\text { Ahmed [30] } \\
2009\end{array}$ & $\begin{array}{l}\text { Prospective } \\
\text { Cohort }\end{array}$ & & & * & $*$ & & $*$ & & & & & * & * & 5 \\
\hline $\begin{array}{l}\text { Pereira [31] } \\
2013\end{array}$ & $\begin{array}{l}\text { Prospective } \\
\text { Cohort }\end{array}$ & & * & $*$ & & * & * & & & & * & $*$ & * & 7 \\
\hline $\begin{array}{l}\text { Llaurado } \\
\text { [34] } 2014\end{array}$ & $\begin{array}{l}\text { Prospective } \\
\text { Cohort }\end{array}$ & & & * & & & $*$ & * & & & * & * & * & 6 \\
\hline
\end{tabular}

Questions marked with asterisk that are fulfilled will award the study one star; fulfillment of non-asterisked columns awards no stars

Selection

1) Representativeness of the exposed cohort:

A) truly representative of the average population; B) somewhat representative of the average population; C) selected group of users; D) no description of the derivation of the cohort

2) Selection of the non-exposed cohort:

A) drawn from the same community as the exposed cohort; B) drawn from a different source; C) no description of the derivation of the non-exposed cohort;

3) Ascertainment of exposure:

A) secure record; B) structured interview; C) written self-report; D) no description

4) Demonstration that outcome of interest was not present at start of study:

A) yes; B) no

Comparability

1) Comparability of cohorts on the basis of the design or analysis:

A) study controls for cohort_; B) study controls for any additional factor

Outcome

1) Assessment of outcome:

A) independent blind assessment; B) record linkage; C) self-report; D) no description

2) Was follow-up long enough for outcomes to occur

A) yes (select an adequate follow up period for outcome of interest); B) no

3) Adequacy of follow up of cohorts

A) complete follow up - all subjects accounted for; B) subjects lost to follow up unlikely to introduce bias; C) follow up rate is adequate and no description of those lost; D) no statement

Scoring algorithm*

\begin{tabular}{llll}
\hline Quality rating & \# Points in Selection Domain & \# Points in Comparability Domain & $\geq 2$ \\
Good & $\geq 3$ & $\geq 1$ & $\geq 2$ \\
Fair & 2 & 0 & $0-1$ \\
Poor & $0-1$ & 0 & \\
\hline
\end{tabular}


factors (duration and type of surgery) with PPCs in bariatric patients [44]. They found that increasing age, BMI, ASA status, metabolic syndrome, OSA, asthma, congestive heart failure, surgical factors were independently associated with PPCs. PPCs and metabolic syndrome were significantly associated with increased postoperative mortality [42]. Many other studies have also reported that OSA patients are at a higher risk for hypoxemia than non-OSA patients [5, 35-38].

\section{Monitoring of NMB}

Residual NMB was monitored in all the included studies by TOFR using acceleromyography before reversal agent, and on admission in the PACU [30-32]. In the general population, residual $\mathrm{NMB}$ increases the incidence and risk of PPCs in a dose dependent manner [16]. To avoid PPCs, neuromuscular monitoring is important to reduce residual NMB; this is even more important in OSA patients as it has been reported as an associated risk factor for early PPCs requiring invasive airway placement or intensive respiratory care [7, 35]. Ideally, before extubation, any residual NMB should be ruled out by quantitative neuromuscular monitoring in a train of four (TOF) supramaximal peripheral nerve stimulations administered over two seconds [45]. A consensus statement on the perioperative use of neuromuscular monitoring was recently published by a panel of clinician scientists with expertise in NMB monitoring [46]. They recommended that whenever a NMBD is administered, neuromuscular function must be monitored by observing the evoked muscular response to peripheral nerve stimulation [46]. The American Society of Anesthesiologists recommends that: 1) patients at increased perioperative risk from OSA should be extubated while awake; 2) full reversal of NMB should be verified before extubation; and 3) when possible, extubation and recovery should be carried out in the lateral, semi-upright, or other non-supine positions [47].

\section{Use of reversal agents}

Several studies have examined sugammadex vs. neostigmine in patients without OSA. Brueckmann et al. and Sabo et al. found that the use of sugammadex vs. neostigmine for NMBD reversal reduced residual NMB in PACU [48, 49]. In a systematic review of 17 RCTs of non-OSA patients, Abad-Gurumeta et al. found a significant reduction in residual NMB with sugammadex vs. neostigmine but no difference in the rate of adverse respiratory events that required tracheal re-intubation [50]. We found some, albeit limited evidence to support a reduction in PPCs in OSA patients receiving sugammadex vs. neostigmine. In a 2017 Cochrane review, significantly less bradycardia occurred in patients who received sugammadex vs. neostigmine [36]. In the OSA patients, Unal et al. also reported less bradycardia in the sugammadex vs. neostigmine group [33].

In the morbidly obese patients, Gaszynski et al. found that sugammadex reversed rocuronium more quickly than neostigmine with a mean time to $90 \%$ of TOF $(2.7$ vs. $9.6 \mathrm{~min}, P<0.05$ ), and a higher TOF at the PACU $(109.8 \%$ vs $85.5 \%, P<0.05)$ [51]. In the obese vs. patients with a normal body mass index, the duration of action of NMBD may be prolonged which may lead to increased incidence of residual NMB in PACU [52]. In both studies, PPCs and the number of OSA patients were not described $[51,52]$. In contrast, in a review of 27 studies with over 1400 patients receiving sugammadex, Monk et al. reported that there were no clinically significant differences in recovery times to a TOFR of 0.9 between patients with and without obesity, following reversal of NMBD with sugammadex [53].

The Society of Anesthesia and Sleep Medicine recommended that OSA patients should be identified and optimized preoperatively and the diagnosed OSA patients who are already on home CPAP device should continue with CPAP perioperatively [54]. These precautions should be taken when NMBD are administered for OSA patients.

\section{Limitations}

There were few studies evaluating the effect of NMBD on postoperative complications in OSA vs. non-OSA patients, and the effect of different reversal agents on postoperative complications in patients with OSA. The sample size of included studies was small. There was a lack of consistent definitions for PPCs among the different studies, and some studies reported symptoms such as cough or breath-holding which are not accepted definitions of PPCs [55]. Most studies used rocuronium in standard intubation and maintenance doses, however, benzylisoquinolines were used by Llaurado et al. (cisatracurium) and Sudre et al. (atracurium) only in the control group to compare with rocuronium. In addition, the effect of opioids and residual anesthetics on postoperative pulmonary complications was not evaluated in the studies. OSA patients with co-existing morbidities such as chronic obstructive pulmonary disease, renal or liver disease were not evaluated. As OSA is associated with significant comorbidities, such as morbid obesity, obesity hypoventilation syndrome, pulmonary hypertension and cardiovascular diseases, it is unclear what the contribution of OSA or its comorbidities are towards PPCs [52]. Only Pereira et al. measured TOF in the PACU. Finally, one study used the STOP-Bang questionnaire to identify high risk OSA and the diagnosis was not confirmed by polysomnography [31]. 


\section{Conclusions}

Our systematic review suggests that OSA patients who received intraoperative NMBD may be at higher risk for postoperative residual neuromuscular blockade, hypoxemia, and respiratory failure. The use of sugammadex was associated with less postoperative pulmonary complications in patients with OSA as compared to neostigmine, however, the evidence was very limited as the studies were of low to moderate quality. Larger, well-designed trials are needed to elucidate the effect of sugammadex on postoperative complications in OSA patients.

\section{Abbreviations \\ AHI: Apnea-hypopnea index; CPAP: Continuous positive airway pressure; ICU: Intensive care unit; NMB: Neuromuscular blockade; \\ NMBD: Neuromuscular blocking drugs; OSA: Obstructive sleep apnea; PACU: Post anesthesia care unit; PPCs: postoperative pulmonary complications; PSG: Polysomnography; RCT: Randomised controlled trial; SDB: Sleep disordered breathing; TOFR: Train of four ratio}

\section{Acknowledgements}

1) Marina Englesakis, MSc, research librarian, University Health Network, Toronto, ON, Canada, for the support with performing the literature search. 2) Shireen Ahmad, MD, Department of Anesthesiology, Northwestern University Feinberg School of Medicine, Chicago, USA, for providing additional data for the systematic review.

\section{Funding}

Department of Anesthesiology and Pain Medicine, University Health Network, University of Toronto.

\section{Availability of data and materials}

All databases are included in the section of Methods and Materials.

\section{Authors' contributions}

The idea for the manuscript was conceived in a meeting chaired by FC, and was attended by RH, JW, MS, AT, DW and MN. RH and AT screened the studies initially. Conflicts were resolved by JW and MS. RH wrote the first draft of the manuscript. JW, MS, FC, DW, MN and AT all reviewed the manuscript and were involved in its critical revision before submission. All authors read and approved the final manuscript.

\section{Ethics approval and consent to participate}

Ethics approval and consent to participate are not needed for systematic review.

\section{Consent for publication}

Not applicable.

\section{Competing interests}

JW reports grants from the Ontario Ministry of Health and Long-Term Care, Anesthesia Patient Safety Foundation and Acacia Pharma outside of the submitted work. DW reports grant from Fisher \& Paykel Healthcare outside of the submitted work. FC reports research support from the Ontario Ministry of Health and Long-Term Care, University Health Network Foundation, ResMed Foundation, Acacia Pharma, Medtronics grants to institution, Up-to-date royalties, STOP-Bang proprietary to University Health Network. MS reports having received peer-reviewed grants from the Canadian Anesthesiologist's Society and the Society of Anesthesiology and Sleep Medicine outside of the submitted work. The other authors report no competing interests.

\section{Publisher's Note}

Springer Nature remains neutral with regard to jurisdictional claims in published maps and institutional affiliations.

\section{Author details}

${ }^{1}$ Department of Anesthesia, Toronto Western Hospital, University Health Network, University of Toronto, 2-405 McLaughlin Wing, 399 Bathurst Street, Toronto, ON M5T 2S8, Canada. ²Department of Anesthesia, Women's College Hospital, Toronto, ON, Canada. ${ }^{3}$ Toronto Sleep and Pulmonary Center, Toronto, ON, Canada. ${ }^{4}$ Department of Anesthesiology and Perioperative Medicine, University Hospital, St. Joseph's Hospital and Victoria Hospital, London Health Sciences Centre and St. Joseph's Health Care, Western University, London, ON, Canada.

Received: 15 March 2018 Accepted: 24 June 2018

Published online: 19 July 2018

\section{References}

1. Nagappa M, Mokhlesi B, Wong J, Wong DT, Kaw R, Chung F. The effects of continuous positive airway pressure on postoperative outcomes in obstructive sleep apnea patients undergoing surgery: a systematic review and meta-analysis. Anesth Analg. 2015;120:1013-23.

2. Peppard P, Young T, Barnet J, Palta M, Hagen EW, Hla KM. Increased prevalence of sleep-disordered breathing in adults. Am J Epidemiol. 2013; 177:1006-14.

3. Finkel KJ, Searleman AC, Tymkew H, Tanaka CY, Saager L, Safer-Zadeh E, et al. Prevalence of undiagnosed obstructive sleep apnea among adult surgical patients in an academic medical center. Sleep Med. 2009;10:753-8.

4. Singh M, Liao P, Kobah S, Wijeysundera DN, Shapiro C, Chung F. Proportion of surgical patients with undiagnosed obstructive sleep apnoea. $\mathrm{Br} J$ Anaesth. 2013;110:629-36.

5. Chung F, Liao P, Elsaid H, Shapiro CM, Kang W. Factors associated with postoperative exacerbation of sleep-disordered breathing. Anesthesiology. 2014;120:299-311.

6. Opperer M, Cozowicz C, Bugada D, Mokhlesi B, Kaw R, Auckley D, et al. Does obstructive sleep apnea influence perioperative outcome? A qualitative systematic review for the Society of Anesthesia and Sleep Medicine Task Force on preoperative preparation of patients with sleepdisordered breathing. Anesth Analg. 2016;122:1321-34.

7. Eikermann M, Fassbender P, Malhotra A, Takahashi M, Kubo S, Jordan AS, et al. Unwarranted administration of acetylcholinesterase inhibitors can impair genioglossus and diaphragm muscle function. Anesthesiology. 2007; 107:621-9.

8. Mokhlesi B, Hovda MD, Vekhter B, Arora VM, Chung F, Meltzer DO. Sleepdisordered breathing and postoperative outcomes after bariatric surgery: analysis of the nationwide inpatient sample. Obes Surg. 2013;23:1842-51.

9. Memtsoudis SG, Stundner O, Rasul R, Chiu YL, Sun X, Ramachandran SK, et al. The impact of sleep apnea on postoperative utilization of resources and adverse outcomes. Anesth Analg. 2014;118:407-18.

10. Benumof $\mathrm{J}$. Creation of observational unit may decrease sleep apnea risk. Anesth Patient Safety Foundation Newsletter. 2002;17:39.

11. Ankam J, Hunter J. Pharmacology of neuromuscular blocking drugs. Contin Educ Anaesth Crit Care Pain. 2004:4:2-7.

12. Murphy G. Residual neuromuscular blockade: incidence, assessment, and relevance in the postoperative period. Minerva Anestesiol. 2006;72:97-109.

13. Murphy GS, Szokol JW, Marymont JH, Franklin M, Avram MJ, Vender JS. Residual paralysis at the time of tracheal extubation. Anesth Analg. 2005; 100:1840-5.

14. Baillard C, Clec'h C, Catineau J, Salhi F, Gehan G, Cupa M, et al. Postoperative residual neuromuscular block: a survey of management. $\mathrm{Br}$ J Anaesth. 2005;95:622-6.

15. Murphy GS, Brull SJ. Residual neuromuscular block: lessons unlearned. Part I: definitions, incidence, and adverse physiologic effects of residual neuromuscular block. Anesth Analg. 2010;111:120-8.

16. Eikermann $M$, Vogt F, Herbstreit F, Vahid-Dastgerdi M, Zenge $\mathrm{MO}$, Ochterbeck C, et al. The predisposition to inspiratory upper airway collapse during partial neuromuscular blockade. Am J Respir Crit Care Med. 2007; 175:9-15.

17. McLean DJ, Diaz-Gill D, Farhan HN, Ladha KS, Kurth T, Eikermann M. Dosedependant association between intermediate-acting neuromuscular blocking agents and PRC. Anesthesiology. 2015;122:1201-13.

18. Grosse-Sundrup M, Henneman JP, Sandberg WS, Bateman BT, Uribe JV, Nguyen NT, et al. Intermediate acting non-depolarizing neuromuscular blocking agents and risk of postoperative respiratory complications: prospective propensity scores matched cohort study. BMJ. 2012;345:e6329. 
19. Bulka CM, Terkhov MA, Martin BJ, Dmochowshi R, Hayes RM, Ehrenfeld JM. Nondepolarizing neuromuscular blocking agents, reversal, and risk of postoperative pneumonia. Anesthesiology. 2016;125:647-55.

20. Fuchs-Buder T, Nemes R, Schmartz D. Residual neuromuscular blockade: management and impact on postoperative pulmonary outcome. Curr Opin Anesthesiol. 2016;29:662-7.

21. Nag K, Singh DR, Shetti AN, Kumar H, Shivashanmugam T, Parhtasarathi S. Sugammadex: a revolutionary drug in neuromuscular pharmacology. Anesth Essays Res. 2013;7:302-6.

22. Abrishami A, Ho J, Wong J, Yin L, Chung F. Sugammadex, a selective reversal medication for preventing postoperative residual neuromuscular blockade. Cochrane Database Syst Rev. 2009;7:CD007362.

23. Moher D, Larissa S, Clarke M, Ghersi D, Liberati A, Petticrew M, et al. Preferred reporting items for systematic review and meta-analysis protocols (PRISMA-P) 2015 statement. Syst Rev. 2015:4:1.

24. Higgins JP, Green S. Cochrane handbook for systematic reviews of interventions version 5; 2011

25. Wells G SB, O'Connell D, Peterson J, Welch V, Losos M, et al. The NewcastleOttawa scale (NOS) for assessing the quality if nonrandomized studies in meta-analyses Ottawa 2014.

26. Phillips B, Ball C, Badenoch D, Straus S, Haynes B, Dawes M. Oxford Centre for evidence-based medicine levels of evidence (may 2001). BJU Int. 2011; 107:870.

27. Llaurado S, Sabate A, Ferreres E, Camprubi I, Cabrera A. Sugammadex ideal body weight dose adjusted by level of neuromuscular blockade in laparoscopic bariatric surgery. Anesthesiology. 2012;117:93-8.

28. Leykin Y, Pellis T, Del Mestro E, Marzano B, Fanti G, Brodsky JB. Anesthetic management of morbidly obese and super-morbidly obese patients undergoing bariatric operations: hospital course and outcomes. Obes Surg. 2006;16:1563-9.

29. Bamgbade OA. Advantages of doxapram for post anaesthesia recovery and outcomes in bariatric surgery patients with obstructive sleep apnoea. Eur J Anaesthesiol. 2011;28:387-91

30. Ahmed S, Nagle A, McCarthy R, Fitzgerald PC, Sullivan JT, Prystowsky J. Postoperative hypoxemia in morbidly obese patients with and without obstructive sleep apnea undergoing laparoscopic bariatric surgery. Anesth Analg. 2008;107:138-43.

31. Pereira H, Xara D, Mendonca J, Santos A, Abelha FJ. Patients with a high risk for obstructive sleep apnea syndrome: postoperative respiratory complications. Rev Port Pneumol. 2013;19:144-51.

32. Sudré ECM, De Batista PR, Castiglia YMM. Longer immediate recovery time after anesthesia increases risk of respiratory complications after laparotomy for bariatric surgery: a randomized clinical trial and a cohort study. Obes Surg. 2015;25:2205-12.

33. Unal DY, Baran I, Mutlu M, Ural G, Akkaya T, Ozlu O. Comparison of sugammadex versus neostigmine costs and respiratory complications in patients with obstructive sleep apnoea. Turk J Anaesth Reanim. 2015:43:387-95.

34. Llaurado S, Sabate A, Ferreres E, Camprubi I, Cabrera A. Postoperative respiratory outcomes in laparoscopic bariatric surgery: comparison of a prospective group of patients whose neuromuscular blockade was reverted with sugammadex and a historical one reverted with neostigmine. Rev Esp Anestesiol Reanim. 2014;61:565-70.

35. Ramachandran SK, Pandit J, Devine S, Thompson A, Shanks A. Postoperative respiratory complications in patients at risk for obstructive sleep apnea: a single-institution cohort study. Anesth Analg. 2017;125:272-9.

36. Hristovska AM, Duch P, Allingstrup M, Afshari A. Efficacy and safety of sugammadex versus neostigmine in reversing neuromuscular blockade in adults. Cochrane Database Syst Rev. 2017;8:CD012763.

37. Dowidar AM, Basuni AS, EL-kalla RS, Eid GM. Influence of severity of obstructive sleep apnea on postoperative pulmonary complications in patients undergoing gastroplasty. Tanta Med J. 2016;44:58-63.

38. Liao P, Yegneswaran B, Vairavanathan S, Zilberman P, Chung F. Postoperative complications in patients with obstructive sleep apnea: a retrospective matched cohort study. Can J Anesth. 2009;56:819-28.

39. Chung F, Mokhlesi B. Postoperative complications associated with obstructive sleep apnea: time to wake up! Anesth Analg. 2014;118:251-3.

40. Mokhlesi B, Hovda MD, Vekhter B, Arora VM, Chung F, Meltzer DO. Sleepdisordered breathing and postoperative outcomes after elective surgery: analysis of the nationwide inpatient sample. Chest. 2013;144:903-14.

41. Dempsey JA, Veasey SC, Morgan BJ, O'Donnell CP. Pathophysiology of sleep apnea. Physiol Rev. 2010;90:47-112.
42. Chebbo A, Tfaili A, Ghamande S. Anatomy and physiology of obstructive sleep apnea. Sleep Med Clin. 2013;8:425-31.

43. Herbstreit F, Peters J, Eikermann M. Impaired upper airway integrity by residual neuromuscular blockade: increased airway collapsibility and blunted genioglossus muscle activity in response to negative pharyngeal pressure. Anesthesiology. 2009;110:1253-60.

44. Schumann R, Shikora SA, Sigl JC, Kelley SD. Association of metabolic syndrome and surgical factors with pulmonary adverse events, and longitudinal mortality in bariatric surgery. Br J Anaesth. 2015;114:83-90.

45. Fassbender $P$, Herbstreit F, Eikermann M, Teschler H, Peters J. Obstructive sleep apnea: A perioperative risk factor. Dtsch Arztebl Int. 2016;113:463-9.

46. Naguib M, Brull SJ, Kopman AF, Hunter JM, Fulesdi B, Arkes HR, et al. Consensus statement on perioperative use of neuromuscular monitoring. Anesth Analg. 2017; XXX:00

47. Practice guidelines for the perioperative management of patients with obstructive sleep apnea. An updated report by the American Society of Anesthesiologists task force on perioperative management of patients with obstructive sleep apnea. Anesthesiology. 2014;120:268-86.

48. Brueckmann B, Sasaki N, Grobara P, Li MK, Woo T, de Bie J, et al. Effects of sugammadex on incidence of postoperative residual neuromuscular blockade: a randomized controlled study. Br J Anaesth. 2015;115:743-51.

49. Sabo D, Jones RK, Berry J, Solan T, Chen J, Morte JB, et al. Residual neuromuscular blockade at extubation: a randomized comparison of sugammadex and neostigmine reversal of rocuronium-induced blockade in patients undergoing abdominal surgery. J Anesthe Clinic Res. 2011;2:6.

50. Abad-Gurumeta A, Ripolles-Melchor J, Casans-Frances R, Espinosa A Martinez-Hurtado E, Fernandez-Perez C, et al. A systematic review of sugammadex vs neostigmine for reversal of neuromuscular blockade. Anaesthesia. 2015;70:1441-52.

51. Gaszynski T, Szewczyk T, Gaszynski W. Randomized comparison of sugammadex and neostigmine for reversal of rocuronium-induced muscle relaxation in morbidly obese undergoing general anaesthesia. $\mathrm{Br} J$ Anaesth. 2012:108:236-9.

52. Joshi SB, Upadhyaya KSV, Manjuladevi M. Comparison of neostigmine induced reversal of vecuronium in normal weight, overweight and obese female patients. Indian J Anaesth. 2015;59:165-70.

53. Monk TG, Rietbergen H, Woo T, Fennema H. Use of sugammadex in patients with obesity: a pooled analysis. Am J Ther. 2017;24:507-16.

54. Chung F, Memtsoudis SG, Ramachandran SK, Nagappa M, Opperer M, Cozowicz C, et al. Society of Anesthesia and Sleep Medicine guidelines on preoperative screening and assessment of adult patients with obstructive sleep apnea. Anesth Analg. 2016;123:452-73.

55. Canet J, Gallart L, Gomer C, Paluzie C, Vallec J, Castillo J, et al. Prediction of postoperative pulmonary complications in a population-based surgical cohort. Anesthesiology. 2010;113:1338-50

\section{Ready to submit your research? Choose BMC and benefit from:}

- fast, convenient online submission

- thorough peer review by experienced researchers in your field

- rapid publication on acceptance

- support for research data, including large and complex data types

- gold Open Access which fosters wider collaboration and increased citations

- maximum visibility for your research: over $100 \mathrm{M}$ website views per year

At BMC, research is always in progress.

Learn more biomedcentral.com/submissions 